\title{
Diz çevresi osteotomilerinin biyomekanik prensipleri
}

\section{Biomechanical principles of osteotomies around the knee}

\author{
Hasan Bombacı
}

\begin{abstract}
Sağlık Bilimleri Üniversitesi, Haydarpaşa Numune Eğitim ve Araştırma Hastanesi, Ortopedi ve Travmatoloji Kliniği, İstanbul
\end{abstract}
Diz çevresi osteotomileri diz protezi konusundaki gelişmelere rağmen halen güncelliğini koruyan geçerli bir tedavi seçeneğidir. Özellikle genç ve aktif hastalarda, diz osteoartrozunun erken dönemlerinde uzun süreli, tatminkâr sonuçlar almak mümkündür. Anormal yük dağılımını telafi etmenin yanı sıra, tek bir bölmeyi içeren menisküs eksiklikleri veya kondral hasar durumunda da onarılmış dokuları korumak için osteotomiler kullanılabilir. Orta yaş osteoartritinde ise zaman kazandırıcı bir cerrahi işlem olarak tercih edilmektedir. Oldukça sık görülen varus deformitelerinde en sık kullanılan yöntem proksimal tibia medial açık kama osteotomisidir. Ancak deformitenin yeri, sebebi ve miktarına bağlı olarak femur distalinde de varus/valgus açı/kapalı kama osteotomisi ya da hem femur hem de tibiada beraberce kombine osteotomiler olarak uygulanabilir. Başarılı sonuç ameliyat öncesi hastanın iyi analiz edilmesi, biyomekanik prensiplere uygun ameliyat tekniği seçimi ve uygulaması ile yakından ilgilidir. Bu sebeple her bir olgu deformite, dizdeki bağların ve diz içindeki menisküs ve kıkırdak gibi diğer yapıların durumu göz önüne alınarak hassasiyetle değerlendirilmelidir. En sonunda da mekanik aksı en uygun pozisyona konumlandıracak cerrahi teknik seçilmelidir.

Anahtar sözcülkler: proksimal tibia; distal femur; osteotomi; biyomekanik
Osteotomies around the knee are still a current treatment option, despite the advances in knee replacement. It is possible to obtain long-term satisfactory results in especially young and active patients with the early stages of knee osteoarthrosis. In addition to compensating for abnormal load distribution, osteotomies can be used to protect repaired tissues in the event of chondral damage or meniscus defects involving a single compartment. It is preferred as a time-buying surgical procedure in osteoarthrosis in middle ages. Proximal tibial medial open wedge osteotomy is the most commonly used method for the quite common varus deformities. However, depending on the location, cause and amount of the deformity, varus / valgus, open / closed wedge osteotomy in the distal femur and combined osteotomies in both femur and tibia can be simultaneously performed. The successful outcome is closely related to the preoperative analysing of the patient and the selection and application of surgical techniques appropriate to the biomechanical principles. Therefore, each case should be evaluated meticulously considering deformity, the condition of ligaments in the knee and other structures such as meniscus and cartilage within the knee joint. Finally, the surgical techniques to reposition the mechanical axis in the most appropriate location, can be chosen.

Key words: proximal tibia; distal femur; osteotomy; biomechanics
D iz çevresi osteotomileri dizdeki tek kompartman artrozlarının tedavisinde çok yaygın kullanılmaktadır. ${ }^{[1,2]}$ Deformitenin kaynağı eklem dışı ise osteotomi "düzeltici osteotomi” olarak kabul edilirken, eklem içi deformitelerde yapılan osteotomilere yük dağılımını başka bir deformite oluşturarak dengelediği için "palyatif osteotomi”ler denir. Bu tekniklerle özellikle erken dönem osteoartrozda (OA) ve genç hastalarda çok daha iyi sonuçlar alınmaktadır. Çoğunlukla varus dizlerde proksimal tibial açık kama osteotomisi (AKO) şeklinde uygulanan osteotomiler, deformitenin yönüne, miktarına, sebebine ve OA'nın etkilediği bölgeye göre tibia proksimal veya femur distal varus/valgus osteotomisi ya da her iki bölgeye beraber uygulanan kombine osteotomiler şeklinde uygulanabilir. Ancak bu osteotomiler uygulanırken osteotomi yapılacak diz bölgesindeki bağların durumları ve karşı ekstremite de hesaba katılmalıdır. Özellikle kronik instabilitelerde primer (primary), sekonder (secondary) ve tersiyer (triple) varus diz olarak da adlandırılan deformitelerde, diz çevresindeki bağ ve yumuşak doku değişikliklerinin deformite planlamasında göz önünde

- İletişim adresi: Prof. Dr. Hasan Bombacı, Haydarpaşa Numune Eğitim ve Araştırma Hastanesi, Ortopedi ve Travmatoloji Kliniği, Tıbbiye Cad. Üsküdar, İstanbul Tel: 0216 - 4144502 / 1590 e-posta: bombacih@hotmail.com

- Geliș tarihi: 20 Ocak $2020 \quad$ Kabul tarihi: 4 Mart 2020 
bulundurulması gerekir. ${ }^{[3]}$ Bunun dışında diz ekleminde kıkırdak yapı yanında femorotibial yük aktarımında etkili olan menisküslerin durumu da önemlidir.

Seçilmiş hastalarda ve uygun endikasyonlarda yapılan diz çevresi osteotomileri ile tatminkâr sonuçlar elde etmek mümkündür. Bunun için gerek ameliyat öncesi planlamada gerekse cerrahi tekniği uygularken biyomekanik prensiplere özen göstermek gerekir. Bu yazıda diz çevresi osteotomilerin uygulanması esnasında göz önünde bulundurulması gereken biyomekanik prensipler ele alınacaktır.

\section{PROKSIMAL TIBIAL OSTEOTOMILER}

\section{Genel Prensipler}

Proksimal tibial osteotomi (PTO) planlanan hastalarda cerrahi tekniğin biyomekanik açıdan yapılan değerlendirmelere göre seçilmesi sonuçlar üzerine doğrudan etkilidir. Çünkü PTO ameliyatı aslında hastanın normalden sapmış olan biyomekanik dengesini yeniden düzenlemek için yapılır. Diz ekleminin aslında normal genç sağ ıklı bireylerde de gelen streslere dayanma sınırları vardır. Yaş ilerledikçe bu sınırlar daralır. Genç ve sağ|ıklı ekleme sahip kişilerdeki normal şartlarda dizin normal doku homeostazisi içerisinde kalan yüklenme miktarları ilerleyen yaşlarda dizi oluşturan kemik ve yumuşak dokuların yapısal temelinde geri dönüşümsüz değişikliklere sebep olabilir. Söz gelişi varus açılanması olan alt ekstremitelerde medial kompartman, valgus açılanması olan dizlerde ise lateral kompartman anormal "bir birim alana binen yük" artışına maruz kalarak bu bölgedeki kıkırdak ve takiben kemiksel değişimlerin oluşmasına ve ilerlemesine sebep olur. Yapılacak osteotominin amacı ise bu yük dağılımını değiştirerek alt ekstremiteye gelen yükün daha dengeli dağıtılmasını sağlamak, dolayısıyla dizin daralmış homeostazis sınırlarını genişletmektir. Burada birincil amaç eklem çizgisini horizontal hale getirmek olsa da hastanın yaşına ve hastalığın etyolojisine bağlı olarak farklı yaklaşımlar gerekir. Söz gelişi varus deformitesi olan orta yaşlı hastalarda mekanik aksta (eksende) $3^{\circ}-6^{\circ}$ arası aşırı düzeltme genel kabul görür. Fakat konjenital varus deformitesi olan hastalarda ağrı çok daha erken yaşlarda da ortaya çıkabilir. PTO yapılması planlanan bu genç hasta grubunda ise aşırı düzeltmeye gerek yoktur. Bu hastalarda mekanik aksı nötrale getirmek yeterlidir. ${ }^{[4,5]}$

Valgus dizlerde ise mekanik aksı hiçbir zaman nötralden ileriye taşınmaz. Çünkü normal dizlerde diz eklemine gelen yükün \%60'ı medial kompartmana biner. Çok aşııı valgus dizlerde bile medial kompartmana binen yük hiçbir zaman \%30'un altına inmediği gösterilmiştir. ${ }^{[4,5]}$ Nötrale getirilen bir mekanik aks ise yaklaşık $5^{\circ}$ lik anatomik ve fizyolojik valgus açısı demektir. ${ }^{[4,5]}$ Bu yüzden nötralden daha varusa taşınan mekanik aks medial kompartmanda çok aşıı bir yüklenmeye ve dizin normal kompartmanında çok hızı bir dejenerasyona sebep olur. Bu yük dağılımının her bir olguda ayrı ayrı değerlendirilerek dengenin sağlanması biyomekanik prensiplere dayanan cerrahi planlama ile mümkün olur.

\section{Hastanın Değerlendirilmesi}

Hastanın biyomekanik olarak değerlendirilmesi ameliyat öncesi hazırlık döneminde başlar. Klinik muayene, yürüyüşün ve duruşun gözlenmesi ve radyolojik değerlendirmelerin her birinin önemi vardır. Bu inceleme esnasında elde edilen veriler ameliyat planlamasında kullanılır. PTO planlanırken üç faktör öncelikle değerlendirilmelidir:

1. Dizdeki hareket sınırlarının değerlendirilmesi (hiperfleksiyon, artmış tibial rotasyon vb.)

2. Femorotibial eklemde yerleşim bozukluğu (subluksasyon vb.)

3. Dizde anatomik bağ lezyonları ve dizdeki anormal hareketlerle ilişkisi

Hastanın yürüyüşü öncelikli değerlendirilmesi gereken konulardan birisidir. Yapılan araştırmada "varus thrust" (addüksiyon momenti) ile yürüyen hastalarda medial kompartmanın aşıı yüklendiği ve dış yan bağlara (DYB) binen yükün fazla olduğu tespit edilmiştir. ${ }^{[6]}$ Addüksiyon momentindeki artış ayakta dikilen hastalarda da görülebilir. Bu konuda yapılan çalışmaların uzun dönem sonuçları da addüksiyon momenti yüksek hastalarda PTO sonuçlarının daha az tatminkâr olduğunu göstermektedir. ${ }^{[3-5]}$ Çünkü addüksiyon momenti ile yürüyen hastalarda kronik posterolateral köşe (PLK) bağ yaralanması olma ihtimali yüksektir. ${ }^{[3-5]}$

Radyolojik değerlendirme her iki alt ekstremitenin ayakta çekilen ortoröntgenografisi ile yapılır. Tek ayak üzerinde dikilirken çekilen grafiler maksimum varus deformitesini gösterdiğinden yanlış sonuçlar verebilir. ${ }^{[4]}$ Bu grafi alt ekstremite dizilimi yanında, eklemdeki bağ lezyonlarının deformiteye katkısı hakkında da fikir verir. Eğer yük altında iken varus dizilimi eklem seviyesinde ise deformitenin bağ lezyonuna bağlı olma ihtimali yüksektir. PTO planlanan hastada radyolojik ideal endikasyonlar; yük altında çekilen diz eklemi AP röntgeninde dizin femorotibial kompartmanlarından birisi daralmış iken diğerinde daralma görülmemesi, patellofemoral (PF) eklemde daralma olmaması ve eklem dışı deformitenin $5^{\circ}$ 'nin altında olması olarak sıralanabilir. ${ }^{[4]}$

Osteotomi planlanırken femur anatomik aksının vertikal aks ile $9^{\circ}$ 'lik, mekanik aks ile $6^{\circ}$ 'lik açı yaptığını göz önünde bulundurmak gerekir (Şekil 1).. ${ }^{4]}$ Çünkü ameliyat öncesi planlamada mekanik aksın önemi büyüktür. Söz gelişi medialden eklemin \%75'inin lateraline gelen mekanik aks tek ekstremitede yük taşırken medial kondilde "havalanma"ya 


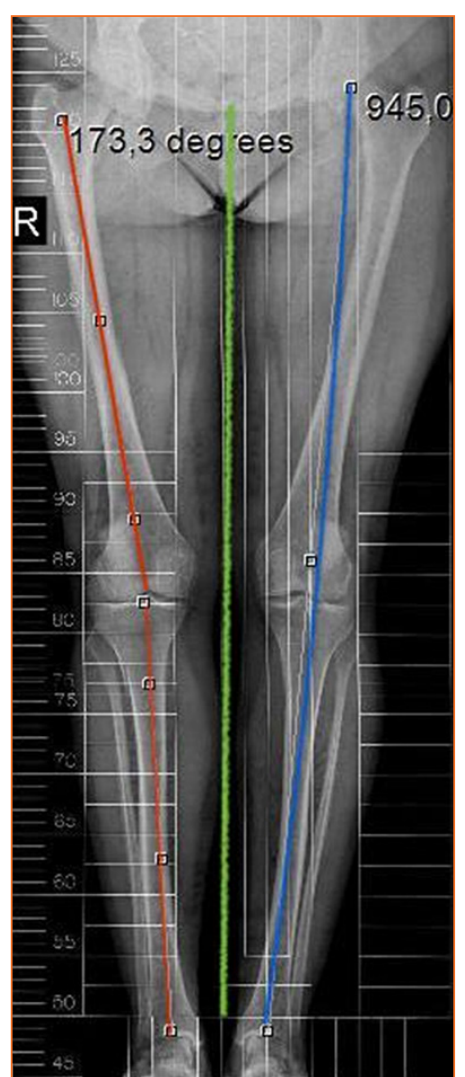

Şekil 1. Ayakta ortoröntgenografide anatomik (kırmızı çizgi) ve mekanik aksın (mavi çizgi) vertikal aksa (yeşil çizgi) göre durumu.

sebep olabilir. Bu aynı zamanda lateral kompartmana gereğinden fazla yük binmesi demek olup lateral kompartmanda kondral hasara, iç yan bağda (IYB) esnemeye ve valgus deformitesinin ilerlemesine sebep olabilir. Bu yüzden varus dizlerde deformitenin düzeltilmesinde genelde tercih edilen yöntem femur başı merkezinden tibia platosunun medial kenarından itibaren \%62'sine gelen noktaya bir hat çizmek, sonra ayak bileği ortasından aynı noktaya ikinci bir doğru çizerek aradaki açıyı ölçmektir (Şekil 2). ${ }^{[4]}$ Bu ölçülen açı varus dizlerde mekanik aksın istenen noktaya taşınması için gereken düzeltme miktarını verir. Ancak PTO menisküs transplantasyonu, kıkırdak lezyonu tamiri yapılan nispeten genç hastalarda da yapılabilir. Bu hastalarda mekanik aks diz ekleminin orta noktasından ileriye taşınmamalıdır.

PTO'dan tibial eğim (TE) de etkilenebilir. TE tibial platonun lateral grafisinde değerlendirilir. Lateral grafide $8^{\circ}$ 'yi geçen bir TE, ÖÇB'de aşırı strese sebep olarak ameliyatın başarısız olmasına yol açabilir. Yapılan çalışmalarda AKO ile TE'nin arttı̆̆ı, kapalı kama osteotomisi (KKO) ile ise azaldığı tespit edilmiştir. ${ }^{[7,8]}$ Bunun sebebi tibianın proksimalinin üçgen şeklinde olmasıdır (Şekil 3). ${ }^{[7]}$ AKO'da tespitte kullanılan plağın yerine

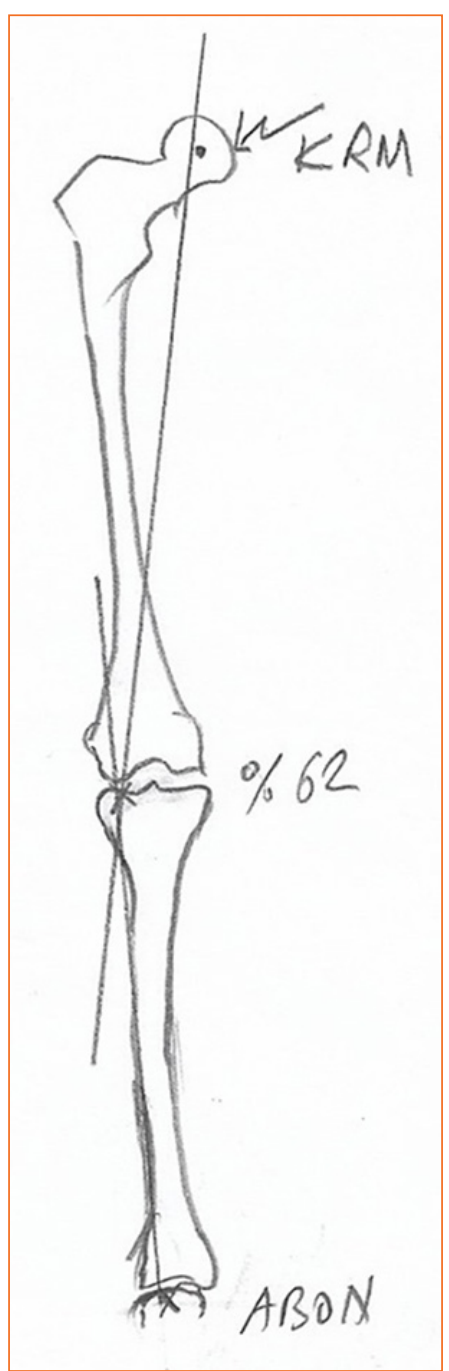

Şekil 2. PTO uygulanan olgularda düzeltme açısının hesaplanması. Kalça rotasyon merkezinden (KRM) tibia platosunun medial kenarından itibaren \%62'sine gelen noktaya bir hat çizilir, sonra ayak bileği orta noktasından (ABON) aynı noktaya ikinci bir doğru çizerek aradaki açı ölçülür. Bu açı düzeltme açısıdır.

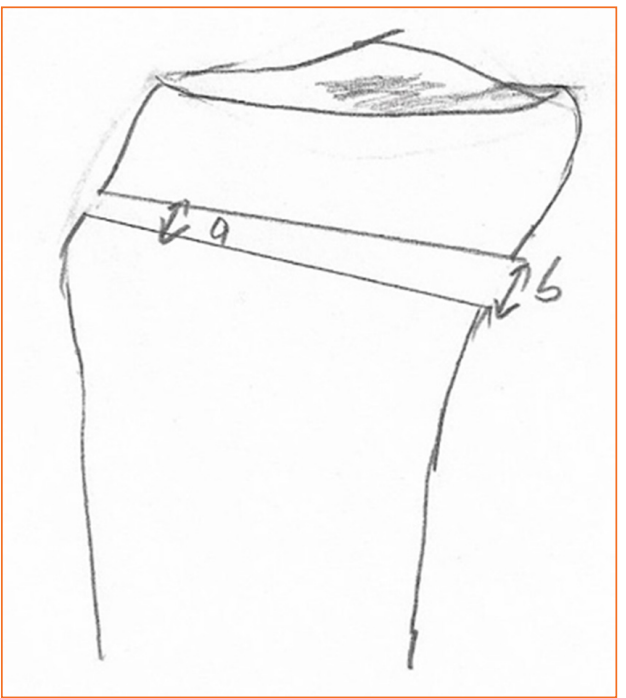

Şekil 3. Tibia üst ucunun üçgen şeklinde olması sebebiyle medialden yapılan AKO'de osteotomi hattının ön kenarı [a] ile arka kenarı [b] arasındaki açıklıklar aynı değildir. 


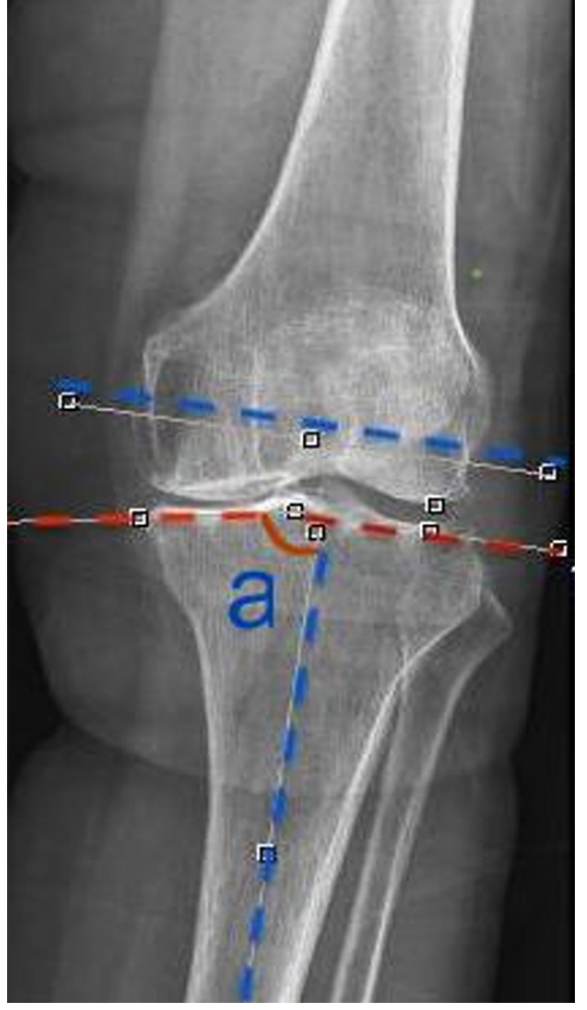

Şekil 4. Tibia platosunun bir tarafının çok aşındığı durumda "yapısal deformite" ortaya çıkabilir. Yapısal deformite tibia orta hattından çekilen çizginin, tibia platosuna teğet çizilen çizgi ile yaptığı açıdır (a açısı). bağ ı olarak bu etki artar ya da azalır. Osteotomi hattının ön kısmındaki her bir milimetrelik değişim, TE'de yaklaşık $2^{\circ}$ 'lik değişime sebep olmaktadır. ${ }^{[8,9]}$ TE'nin artması ile tibianın öne kayması da artmakta ve dolayısıyla ÖÇB'ye binen yükün de artmasına sebep olmaktadır. ${ }^{[8,9]}$ Benzer şekilde TE'in azalması da arka çapraz bağa binen yükü arttırmaktadır. ${ }^{[8,10,11]}$ Shelburne ve ark. -/+ 5 derecelik TE'nin değiştiği durumlarda ÖÇB'ye binen yükün -75 ila +80 Newton arasında değiştiğini tespit etmişlerdir. ${ }^{[8]}$ Giffin ve ark. TE'in $5^{\circ}$ 'lik arttırıldığı dizlerde tibianın $4 \mathrm{~mm}$ öne geldiğini tespit etmiştir. ${ }^{[12]}$ Agneskirchner ve ark. da benzer sonuçlar bulmuşlar ve bu da arka çapraz bağ (AÇB) yetersizliği olan dizlerde TE'nin arttırılmasının etkili olabileceği fikrini doğurmuştur. ${ }^{[13]}$ Brandon ve ark. ÖÇB kopuk ve normal dizlerde yaptıkları TE ölçümlerinde standart sapmayı oldukça yüksek değerde bulmuşlar ve birkaç derecelik değişimin çok da etkili olmayabileceğini ileri sürmüşlerdir. ${ }^{[14]}$ Her ne kadar mevcut literatürde TE'nin belli sınırlarda değişmesinin klinik etkileri konusunda tam bir fikir birliği yoksa da, özellikle bağ lezyonu olan dizlerde PTO uygularken TE'nin değişmemesine özen göstermek gerekir. Bununla beraber daha önceki kırık ya da cerrahi işlemlere bağlı olarak TE'si artmış ya da azalmış hastalarda PTO planlanırken TE’yi düzeltici bir tekniğin tercih edilmesi gerekir.

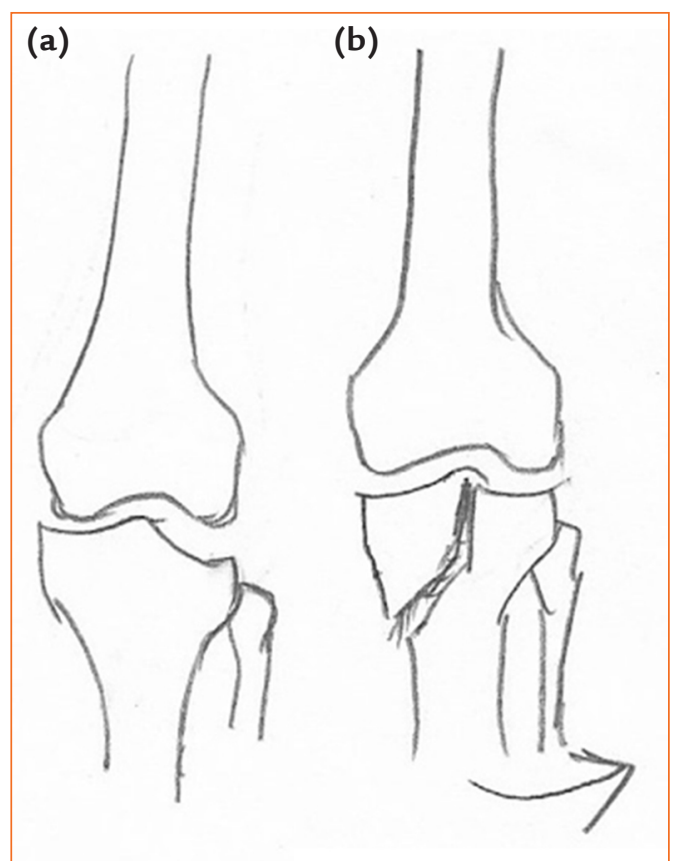

Şekil 5. a, b. "Yapısal deformite" mevcut tibia üst uçta "tibial kondiler valgus osteotomisi" tekniği. Eklem içi deformitede (a) "teeter-totter" etkisini gidermek için tek kondili içeren osteotomi (b) yapılabilir.

Tibianın bir kompartmanının aşındığı olgularda "yapısal deformite" de ortaya çıkabilir. Yapısal deformiteyi ölçmek için değişik yöntemler tarif edilmiştir. ${ }^{[15]}$ Bunlardan bir tanesinde tibia orta hattından çekilen çizginin, tibia platosuna teğet çizilen çizgi ile yaptığı açıdır (Şekil 4). Yapısal deformiteler "teeter-totter" (tahterevalli) etkisine sebep olur. Eğer medial plato ileri derecede çökmüş ise ya da tibia platosu ortasındaki osteofitler ileri derecede yükselmiş ise dizin pozisyonuna bağlı olarak yük sağlam platoya aktarıldığında tibia platosu ortasındaki yükseklik yükün diğer tarafa aktarılmasını engelleyecektir. Bu sebeple de PTO işlemi başarısız olacaktır. Bu tür eklem içi deformitelerde "tibial kondiler valgus osteotomisi" tekniği kullanılabilir. ${ }^{[15]}$ Bu osteotomi eklem uyumunu sağladığı gibi eklem stabilitesine de katkıda bulunur (Şekil 5).

Diz ekleminde bir diğer anormal yüklenme sebebi rotasyonel deformitelerdir. Varus/valgus deformitesi olan hastalarda bazı durumlarda deformitenin konveks tarafinda da OA gelişebilmektedir. Bu olgularda rotasyonel deformitelerin etkili olduğu düşünülmektedir. Alt ekstremitede iç rotasyon olan hastalarda lateral tibiofemoral kompartmanda OA gelişirken, eksternal femoral rotasyon olan hastalarda medial tibiofemoral kompartmanda OA'ya sebep olabilir. ${ }^{[16]}$ Rotasyonel anormallikler PF eklemde de 


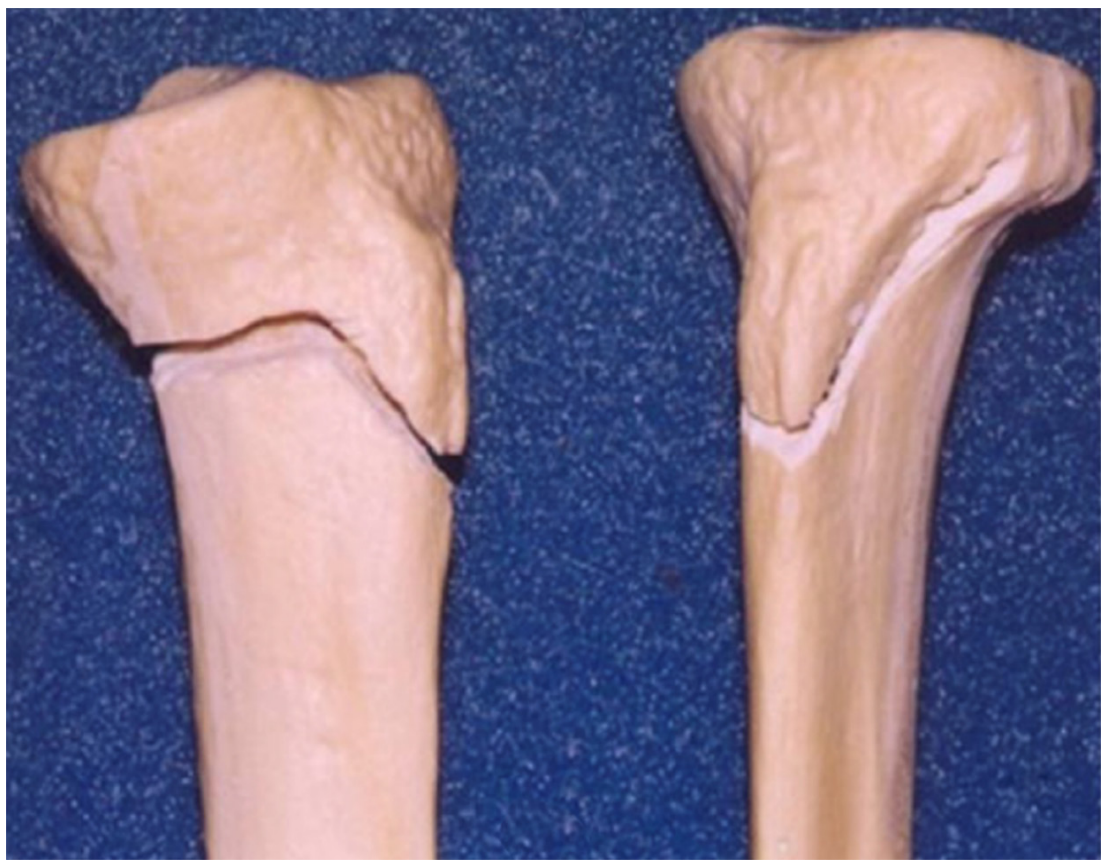

Şekil 6. İki planlı retrotüberkül PTO'de tibia üst ucunun medial ve anterolateralden görünüşü. Tüberositas tibia proksimal parçada kaldığı için PF ekleme binen yük artmaz. (Fotoğraf, Prof. Dr. Irfan Esenkaya'nın izniyle kullanılmıştır).

anormal yüklenmelere sebep olabilir. Liska ve ark. yaptıkları çalışmada anormal femoral anteversiyonu düzeltmek için yapılan derotasyon osteotomilerinin medial PF eklemde stresi arttırırken, lateral kısımda stresi azalttığını tespit etmişlerdir. ${ }^{[17]}$ Planlama yaparken alt ekstremitedeki deformasyonları 3 boyutlu düşünmek gerekmektedir. Çünkü femoral anteversiyonu düzeltmek için kullanılan distal femoral derotasyon osteotomisi yapılırken mekanik aks dikkate alınmazsa valgusun artma ihtimali mevcuttur. Bu da beraberinde PF eklemde artmış stres demektir. Imhoff ve ark. yaptıkları çalışmada femurun fizyolojik eğimini dikkate almadan, femur mekanik aksına dik yapılan osteotomilerin istemsiz valgus deformitesini önlediğini tespit etmişlerdir. ${ }^{[18]}$ Rotasyonel deformiteleri en iyi ortaya koyan radyolojik değerlendirme bilgisayarlı tomografi olduğu için ameliyat öncesi deformite analizi ve planlamada yeri önemlidir.

Diz çevresi osteotomilerin planlanmasında bağların önemi yukarıda vurgulanmıştı. Bu hastalarda bağ muayenesi yaparken dış yan bağ (DYB) yetersizliği $0^{\circ}$ ve $30^{\circ}$ fleksiyonda varus stres testi ile değerlendirilir. Açılma milimetre olarak değerlendirilir. PLK $\operatorname{diz} 30^{\circ}$ ve $90^{\circ}$ fleksiyonda iken tibianın dış rotasyona zorlanması sonucunda tibianın posteriora subluksasyonun miktarına bakarak değerlendirilir. Bu konudaki muayene yöntemleri bu bölümün esas konusunun kapsamı dışında olduğu için ayrıntıya girilmemiştir.

\section{Açık kama osteotomisi (AKO)}

AKO'nun biyomekanik açıdan en büyük avantajı düzeltmenin tam istenen miktarda yapılabilmesidir. Dezavantajı ise ekstansör mekanizmanın gerilmesidir. İç yan bağ (IYB) da bir miktar gerilse de bağın yüzeysel kısmı gevşetilerek bu kısmen önlenebilir. Bir diğer dezavantajı TE'nin artmasına sebep olmasıdır. ${ }^{[7]} \mathrm{Bu}$ sebeple bu teknik dizin öne instabilitesi olan hastalarda çok uygun değildir. Daha çok erken dönem OA olan genç hastalar için tercih edilebilir. Patellofemoral (PF) eklem açısından değerlendirildiğinde ise, AKO patella alta olan hastalarda avantaj sağlarken, patella infera olan hastalarda kontrendikedir. Çünkü AKO ile ekstansör mekanizma daha fazla stres altında kalarak PF eklemde OA gelişimine sebep olabilir.

Son zamanlarda "biplanar" (iki planlı) osteotomiler genel kabul görmektedir. Bu osteotomi tek planlı osteotomiye göre osteotomi hattının daha distalden yapılmasına imkân sağlar. ${ }^{[1,19]}$ Ayrıca AKO'da tek planlı osteotomiye göre daha az "boşluk volümü" oluşmasına sebep olur. Dolayısıyla daha stabildir ve daha az grefte ihtiyaç doğurur. İki planlı osteotomiler iki türlü yapılabilir. Birincisinde yatay plandaki osteotomi hattına ilave edilen dikey hat osteotomi hattından proksimale doğru giderken ikincisinde distale doğru gider (Şekil 6). ilk durumda PF eklem aynı tek planlı osteotomilerde olduğu gibi stres altında kalır. Fakat ikinci osteotomi tekniğinde 


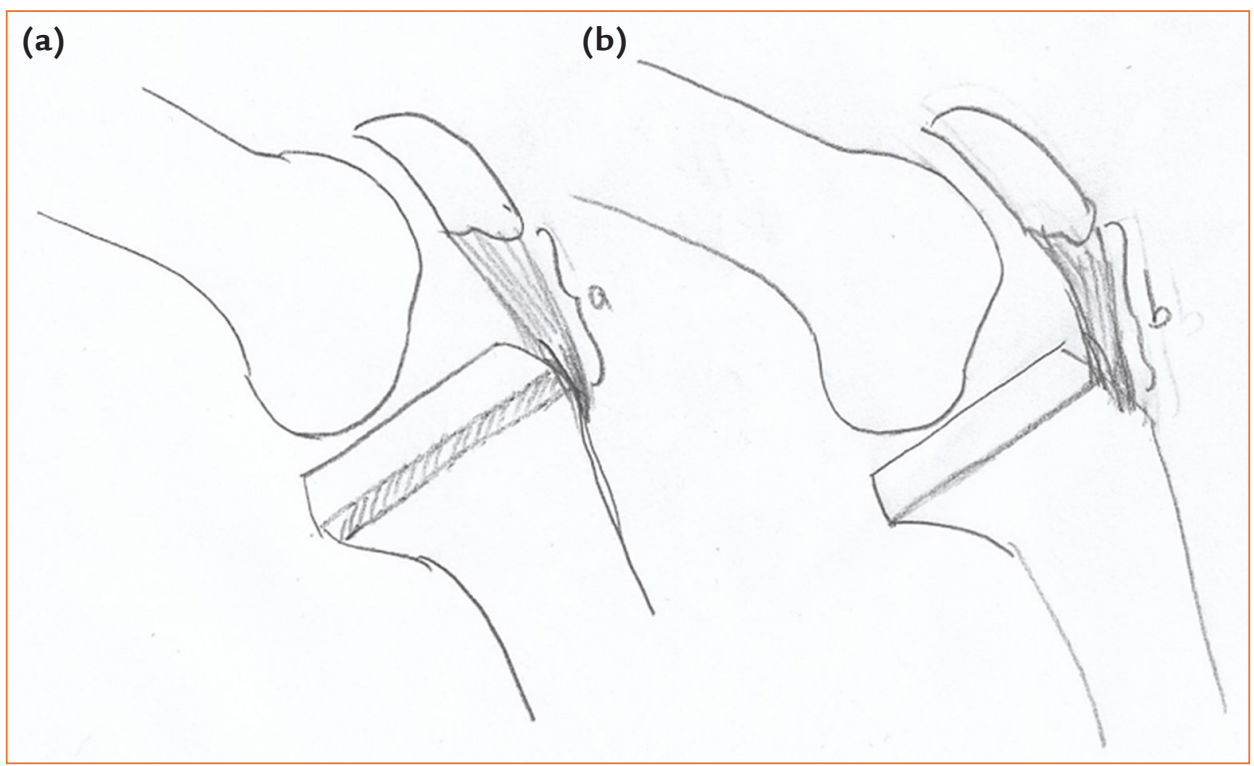

Şekil 7. a, b. Proksimal tibia KKO'de tüberositaz tibianın üst kısmındaki mesafe kısaldığı için [a>b] ekstansör mekanizmadaki basınç azalır. KKO'si öncesi (a) ve sonrası (b); kemik blok çıkarıldıktan sonra proksimal tibia ve ekstansör mekanizmanın durumu.

tüberositas tibia proksimal parçada kalacağından PF ekleme ilave bir stres binmez. ${ }^{[1,19]}$ Dolayısıyla bu osteotomi tekniği PF kondromalazisi olan hastalarda da tercih edilebilir. ${ }^{[20]}$

\section{Kapalı kama osteotomisi (KKO)}

KKO'nun en önemli biyomekanik avantajı TE'nin azalmasıdır. Dezavantajı ise planlanan düzeltme miktarının ayarlanmasındaki güçlüklerdir. Daha çok ileri yaşta olup OA'sı ilerlemiş olan hastalarda tercih edilir. TE azalması sebebiyle öne laksitesi olan, ÖÇB yırtığına bağı OA gelişen hastalarda tercih edilebilir. Çünkü öne laksitesi olan hastalarda platonun posteriorunda aşınma daha belirgin olur. KKO'nun ÖÇB'ye binen stresi de azalttığı bilinmektedir. Yamaguchi ve ark yaptığı çalışmada tibianın anterior KKO sonucu tibianın öne kaymasının ve ÖÇB'ya binen yüklerin azaldığını ancak, işin içine tibanın internal rotasyonu girince bu etkisinin kaybolduğunu tespit etmişlerdir. Yazarlar ÖÇB'nin tibianın internal rotasyon kuvvetlerine karşı önemli bir görevi olabileceğini ileri sürmüş̧lerdir. ${ }^{[21]}$

KKO'nun bir diğer endikasyonu patella inferası olan hastalardır. Çünkü AKO yapılan olgularda ekstansör mekanizma gerileceği için patella inferası olan olgularda bu stres çok daha fazla artar ve hastada ekstansör mekanizmanın aşırı stres altında kalmasına bağı $O A$ ortaya çıkar veya ilerler. KKO'da ise ekstansör mekanizma gevşer ve ekstansör mekanizmada stres azalır (Şekil 7).
Smith ve ark AKO ve KKO yapılan hastaları karşılaştırdığı çalışmada AKO yapılan hastalarda anlamlı miktarda TE değişimi, patellar yükseklikte azalma ve kalçadiz-ayak bileği açısı değişimi bulurken, klinik sonuçlar, işlev ve komplikasyonlar açısından iki teknik arasında anlamlı bir fark tespit edememişlerdir. ${ }^{[2]}$ Proksimal tibial KKO, femoral ve tibial deformitelerin beraber olduğu durumlarda da tercih edilebilir. Ancak bu hastalarda osteotomiden sonra tibial oblikliğin $10^{\circ}$ 'nin altında kalmasına ve mevcut başlangıç valgus deformitesinin $8^{\circ}$ 'den daha az açıda olmasına özen göstermek gerekmektedir.

\section{Kubbe (Dome) osteotomisi}

PTO, AKO ve KKO dışında "kubbe osteotomisi" şeklinde de yapılabilir. Kubbe osteotomisinin de avantaj ve dezavantajları vardır. Güneş ve ark yaptığı çalışmada proksimal tibia açık fokal kubbe osteotomisinin diz ekleminde yüzeyel iYB'yi gererek medial laksiteyi etkili bir şekilde azalttığını bildirmişlerdir. ${ }^{[22]}$

\section{Băg lezyonu olan dizlerde yapılan proksimal tibial osteotomi (PTO)}

Varus deformitesine eşlik eden bir diğer tablo dizdeki bağların bir ya da daha fazlasının hasarlı olduğu durumlardır. Bunların arasında ÖÇB yetersizliği en sık karşılaşılan durumdur. Bu hastalarda ağrı dışında dizde instabilite şikayetleri de mevcuttur. Alt ekstremitedeki frontal ve sagittal düzlemdeki dizilim bozukluklarına diz eklemindeki lateral ya da posterior 


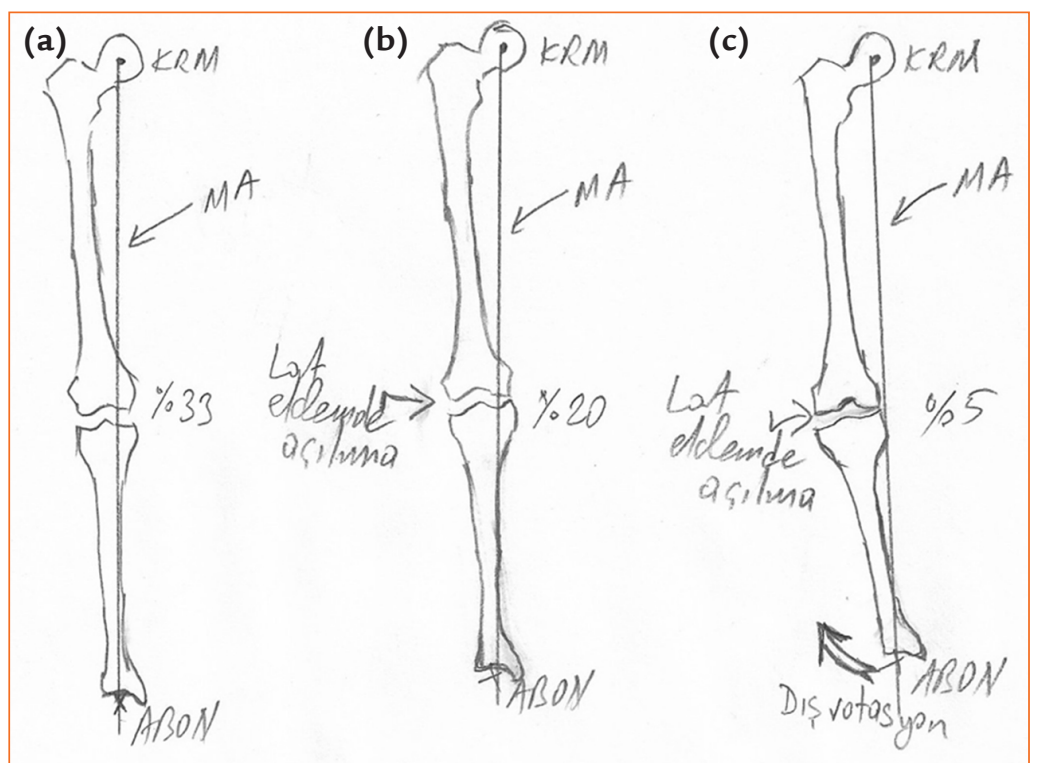

Şekil 8. a-c. "Primer" (a), "sekonder" (b), "tersiyer" (c) varus deformitesinde mekanik aksın diz eklemindeki konumu. Sekonder varusta dizin lateral yapılarında esneme ve diz ekleminin lateralinde açılma başlar. Tersiyer varusta dizin posterolateralindeki esneme ilerleyerek posterolateral köşede esneme ve rekürvasyon deformitesi ortaya çıkar (KRM, kalça rotasyon merkezi; MA, mekanik aks; $\mathrm{ABON}$, ayak bileği orta noktası). subluksasyon da eşlik edebilir. Bu yüzden alt ekstremitedeki dizilim bozuklukları "primer varus", "sekonder varus" ve "tersiyer varus" olarak sınıflanmıştır. [21] Bu sınıflama temelde mekanik aksın geçtiği yere göre yapılmakla beraber, dizilim bozukluğuna eşlik eden dizin posterolateralindeki yapıların yetersizliğine bağIı bu bölgede meydana gelen ayrışmaya dayanır (Şekil 8). "Primer varus" dizin fizyolojik varus pozisyonuna ilave olarak menisektomi gibi sebeplerle dizdeki varus deformitesinin arttığı durumlarda da ortaya çıkar. Dizdeki $3^{\circ}$ 'lik varus açılanması medial kompartmandaki yükü iki katına çıkarır. ${ }^{[5]}$ Medial kompartmanda yoğunlaşan yükler zaman içerisinde lateral kompartmandaki bağ ve adalelerde gerilmeye sebep olur. Bu artmış strese tensor fasya lata, biseps femoris ve gastroknemius adaleleri direnç gösterse de bir müddet sonra eklemin lateralindeki yukarıda isimleri sayılan yapılar esneyerek, mekanik aks bir miktar daha mediale kayar. Bu durum "sekonder varus" olarak adlandırılır. Varus deformitesi arttıkça laterale binen stres de artarak dizin PLK'deki yapıların esnemesine, tibia dış rotasyonunun artmasına ve dizdeki deformiteye hiperekstansiyon komponentinin de ilave olmasına sebep olur. ${ }^{[3]}$

Ameliyat öncesi planlamada bağ lezyonlarının da hesaba katılması gereken bu hastalarda tedavi yaklaşımı da özellik gösterir. Son zamanlarda PTO ile bağ rekonstrüksiyonlarının aynı seansta yapılma eğilimi vardır. Ancak bağ lezyonları da farklı miktarda olabilir. Sözgelişi ÖÇB ve AÇB'de bariz bir hasar olmasa da anormal yüklenmeye bağlı olarak zaman içerisinde daha sınırlı miktarda esneme ve yetersizlik ortaya çıkabilir. Bu yüzden "sekonder varus"lu dizlerde önce yalnız PTO yapılarak takip etmek daha uygun olabilir. Çünkü dizdeki varus yüklenmesi düzelince lateralde esneyen yapıların toparlanma ihtimali vardır. Eğer bağ rekonstrüksiyonu gerekirse sonra da yapılma şansı vardır. Ancak "tersiyer varus" olan dizlerde bariz bir ÖÇB yetersizliği de varsa, ÖÇB yetersizliğini tek başına tedavi etmek yeterli olmaz. Çünkü kısa süre sonra başarısızlıkla sonuçlanır. Bu yüzden ÖÇB rekonstrüksiyonu ile beraber dizilimi düzeltici osteotomi de gerekir. PTO ve ÖÇB rekonstrüksiyonu aynı seansta da yapılabilir. Önce PTO yapılıp iyileştikten sonra, ilerleyen zamanda ÖÇB rekonstrüksiyonu ikinci seansta da yapılabilir. İlk durumda artrofibrozis gibi komplikasyonların sıklığı daha yüksektir. Eğer "tersiyer varus" gelişmiş ve "posterolateral köşe”" (PLK) hasarı da meydana gelmiş ise PLK bağ rekonstrüksiyonu da planlanan cerrahi işlemlere ilave edilmelidir.

Diğer taraftan PTO'nun TE'de değişikliğe sebep olarak ÖÇB ve AÇB'ye binen yükün artmasına sebep olabilir. Yapılan çalışmalarda AKO ile TE'nin arttığı, KKO ile ise azaldığı tespit edilmiştir. ${ }^{[7,8]} \mathrm{Bu}$ da AÇB yetersizliği olan dizlerde TE'nin arttırılmasının, tersine ÖÇB yetersizliği olanlarda ise TE'nin azaltılmasının etkili olabileceği fikrini doğurmuştur. ${ }^{[13]}$ Bu konu PTO'nun TE üzerine etkileri konusunda daha ayrıntılı tartışılmıştır. 


\section{DISTAL FEMORAL OSTEOTOMILER (DFO)}

\section{Genel prensipler}

DFO'ler izole lateral kompartman OA ve travma sonrası OA'da iyi sonuçlar veren bir cerrahi yöntemdir. Ancak dizdeki valgus deformitesi üç boyutludur. Çünkü valgus deformitesinde artış " $Q$ açısı"nda artış ile beraber patellanın femur lateral kondiline yer değiştirmesine ve PF instabiliteye, bu bölgede stres artmasına sebep olur. Tibia platosunun şekli itibarı ile lateral platonun medialden farklı olarak konveks olması menisküsün yük taşıma işlevini arttırmaktadır. Dolayısıyla da menisektomi lateral kompartmanda yük dağılımı, şok absorbsiyonu ve propriyosepsiyon işlevini çok değiştirerek ilerleyici OA'ya sebep olur. Bu yüzden DFO'lar lateral menisküs defekti olan, kıkırdak hasarı olan, kronik IYB yetersizliği olan hastalar yanında PF instabilitesi olan genç hastalarda da kullanılabilir. Ancak tibia üst ucunu ilgilendiren kusurlu kaynamalara bağlı deformitelerde PTO daha uygun olabilir. Lateral kompartmanda gelişen $\mathrm{OA}$ olgularında medial kompartmanda kıkırdak hasarı Outerbridge'e göre en fazla 3 ise, parsiyel menisektomi uygulanan hastalarda intakt bir menisküs kalıntısı var ise, aşırı düzeltmeden distal femoral varus osteotomisi uygulanabilir. $25^{\circ}$ 'den az sabit fleksiyon kontraktürü veya $20^{\circ}$ 'den fazla olan hiperekstansiyon deformitesi, $15^{\circ}$ 'e kadar valgus deformitelerinde DFO'lar tercih edilebilir. ${ }^{[23]}$

\section{Distal femoral açık kama osteotomisi (DFAKO)}

Valgus dizlerde deformitenin kaynaklandığı yer çoğunlukla distal femurdur. Bu sebeple DFO yapılması cazip gelse de aslında valgus deformitesi olan pek çok vakada lateral femoral kondilin hipoplazik olduğunu göz önünde bulundurmak gerekir. Lateral femur kondildeki hipoplaziye bağlı olarak DFO'dan sonra deformite ekstansiyonda düzelse de diz fleksiyona gelince devam eder. Bu sebeple bazı olgularda deformitenin PTO ile düzeltilmesi daha uygun olabilir. Bu olgularda proksimal tibia medial KKO yapılabilir. Ancak bu hastalarda da tibia eklem düzleminin değişme riski vardır. Buna bağlı olarak da PF eklemde, özellikle medial tarafta aşırı stres artışı meydana gelebilir. Bu yüzden osteotomi sonrası eklem çizgisinin frontal planda eğiminin artacağı durumlarda distal femur lateralinden AKO tercih edilebilir. DFAKO'de "tek planlı" ya da "iki planlı" olacak şekilde iki türlü yapılabilir. Pietsch ve ark. bu iki osteotomi şeklini karşılaştırdıkları çalışmada osteotomi tekniğinin aksiyel ve torsiyonel sertliği anlamlı derecede etkilemediğini ancak, iki planlı osteotominin eksternal torsiyon direncinin biraz daha fazla olduğunu tespit etmişlerdir. ${ }^{[24]}$
DFAKO'nun bir diğer etkisi PF eklem üzerinedir. Tüberositas tibiayı da mediale kaydırarak $Q$ açısının düzelmesini sağlayan bu osteotomi ile sublukse patella redükte olur ve lateral PF eklemdeki basınç da azalmış olur. ${ }^{[25]}$ Burada mekanik aksın medialden \%45-47 seviyesine getirilmesi amaçlanır. Bu da $1^{\circ}-2^{\circ}$ lik fizyolojik varustur. Mekanik aksın bundan fazla yer değiştirmesi aşırı düzeltmeye sebep olur. AKO istenen miktarda düzeltmenin yapılmasını kolaylaştırsa da açma sonucu oluşan boşlukta kaynama problemi ortaya çıkma ihtimali de daha yüksektir.

\section{Distal femur kapalı kama osteotomisi (DFKKO)}

Valgus deformitelerinde distal femur medial KKO'su sık tercih edilir. Ancak varus KKO'da kuadrisepsin "çalışma mesafesi” kısalır. Brinkman ve ark. tek planlı osteotominin ekstansör mekanizmadaki kayma mekanizmasını bozduğunu ileri sürerek KKO'nun 2 planlı yapılmasını önermiştir. ${ }^{[23]}$ van der Woude ve ark. distal femoral varus osteotomisi uygulanan olgularda iki planlı osteotomilerle tek planlı olanları karşılaştırmışlar, iki planlı osteotomilerde kaynama süresinin daha kısa olduğunu tespit etmişlerdir. ${ }^{[26]}$

Wylie ve ark. yaptıkları sistematik gözden geçirmede genu valgus sebebi ile distal femoral osteotomi uygulanan hastaları analiz etmişlerdir. ${ }^{[27]}$ Distal femur medial KKO uygulanan olgularla lateral AKO uygulanan vakaları karşılaştırmışlardır. Yazarlar bu ameliyatlar sonucunda hastaların genelde yaşam kalitesi açısından sonuçlardan memnun olduklarını ancak yeniden ameliyat oranının yüksek olduğunu tespit etmişlerdir. Ancak iki teknik arasında anlamlı bir fark bulamamışlardır. ${ }^{[27,28]}$ Quirno ve ark. da distal femoral varus osteotomisi yapılan hastalarda sonuçların iyi olduğunu, $5^{\circ}$ 'lik aşırı düzeltmenin eklemdeki "kontak basıncını" normale çok yaklaştırdığını belirtmişlerdir. ${ }^{[29]}$

\section{"Dome" (kubbe) osteotomisi}

Femur distalinde kubbe şeklinde yapılan osteotomide değişik tespit yöntemleri kullanılabilir. Eksternal fiksatör kullanılan olgularda en önemli avantajı daha az yumuşak diseksiyonu yapılarak deformitede 3 planIı düzeltme yapabilmektir. Varus-valgus düzeltmesi yanında gerekirse kaydırma, fleksiyon-ekstansiyon ve uzatma yapılabilir. Diğer avantajları ise bacakta uzunluk farkı yaratmadan deformitenin düzeltilmesi, metafizden yapıldığı için gerek yüzey alanının geniş olmasına bağlı, gerekse kanlanma avantajları sebebiyle kaynama problemi olmaması olarak sıralanabilir. ${ }^{[25]}$

\section{KOMBINE OSTEOTOMILER}

Femur ve tibiayı tutan deformitelerde kombine osteotomiler de tercih edilebilir. Bu deformitelerde 


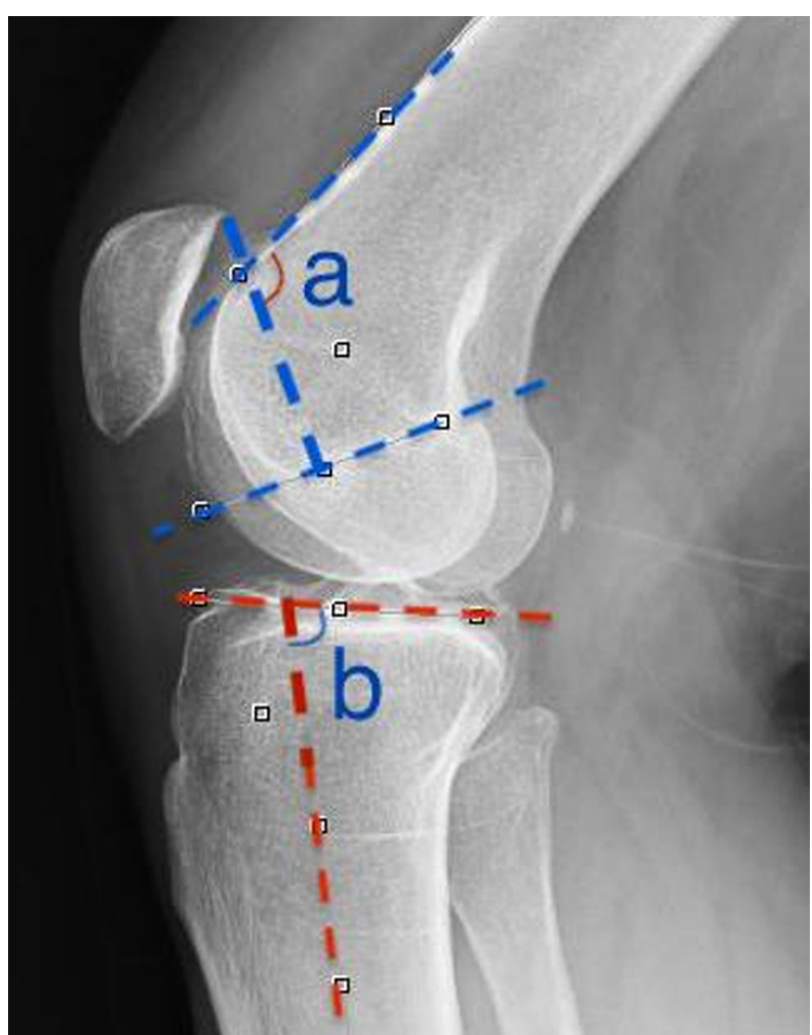

Şekil 9. İzole femur ve tibiayı ilgilendiren deformitelerde her bir kemikte var olan deformiteler ayrı ayrı ölçülür. Femurdaki deformite femur anterior korteksten geçen çizginin Blumensaat çizgisine dik olan çizgi ile (mavi kesik çizgiler) yaptığı açı [a], tibiadaki deformite tibial eğim (kırmızı kesik çizgiler) açısı [b] ölçülerek hesaplanır.

DFAKO ile proksimal tibia medial KKO'su beraber uygulanabilir. Femur ya da tibianın $10^{\circ}$ 'den büyük deformitelerinde, deformitenin olduğu bölgeden yapılan osteotomiler eklem çizgisinin aşırı eğimli olmasına sebep olur. Bu durum eklemde yatay kuvvetlerin artmasına dolayısıyla yapılan müdahalenin başarısız olmasına sebep olur. Bu durumlarda düzeltmenin hem femurdan hem de tibiadan yapılması makul seviyelerde eklem çizgisi eğimine sebep olarak ekleme gelen yüklerin dengeli dağılmasını sağlar. Ayrıca tibianın $10^{\circ}$ 'den büyük deformitelerinde AKO sonrası osteotomi hattının stabilitesinde de azalma beklenir. KKO'da ise büyük miktarda kemik çıkarılması gerekeceğinden sonrasında yapılacak diz protezi ameliyatlarında teknik zorluklar ortaya çıkabilir. Frontal ve aksiyal planda femoral kötü kaynama sonucu dizde OA gelişmeye başlayan olgularda da deformitenin düzeltilmesi femurdan yapılırken, OA'ya yönelik işlemler PTO yöntemi ile yapılabilir.

\section{Anti rekurvatum osteotomileri}

Anti rekurvatum osteotomisinde planlama yaparken yük altında lateral uzun bacak grafisi de gerekir. Bu grafide femoral rekurvatum hesaplanırken; Blumensaat çizgisi ile femur anterior korteks arasındaki açı, tibia rekurvatumu hesaplanırken ise; TE'nin hesaplanması gerekir (Şekil 9). Bu deformiteler poliomyelit sekeli olan hastalarda olduğu gibi nörolojik sebeplerden kaynaklanabilir ve bu durumda diz ekleminin tamamını ilgilendirebilir. Bundan başka travma sonrası fiz hasarlarına bağlı ya da deformite ile iyileşmiş kırıklarda olduğu gibi yalnız femur ya da tibiayı ilgilendiren deformiteler sonrası da ortaya çıkabilir. Bu deformiteleri düzeltilirken nöromusküler hastalıklara bağlı olan olgularda deformitenin tamamının düzeltilmemesi gerekir. Çünkü hasta mevcut kuadriseps zayıflığına bağlı olarak dizini kilitleyemediği için yürümenin basma fazında dizini kilitlemek için bir miktar hiperekstansiyona ihtiyaç duyar. Diğer izole femur ve tibiayı ilgilendiren deformitelerde her bir kemikte var olan deformiteler ölçülerek (femurda; femur anterior korteksten geçen çizginin Blumensaat çizgisine dik olan çizgi ile yaptığı açı, tibiada; negatif TE) o bölgeye yönelik osteotomi planlanarak yapılır (Şekil 9). Düzeltmelerde deformitenin tersine osteotomiler (fleksiyon tipi deformitede ekstansiyon osteotomisi gibi) kullanılabilir. Osteotominin yeri ve miktarına bağlı olarak hem femurda hem de adale çalışma mesafelerinde kısalmalar, sinir hasarları ortaya çıkabilir. ${ }^{[30]}$

\section{KAYNAKLAR}

1. Elmalı N, Esenkaya I, Can M, Karakaplan M. Monoplanar versus biplanar medial open-wedge proximal tibial osteotomy for varus gonarthrosis: a comparison of clinical and radiological outcomes. Knee Surg Sports Traumatol Arthrosc 2013;21(12):2689-95. Crossref

2. Smith TO, Sexton D, Mitchell P, Hing CB. Opening- or closingwedged high tibial osteotomy: A meta-analysis of clinical and radiological outcomes. Knee 2011;18(6):361-8. Crossref

3. Hughston JC, Jacobson KE. Chronic posterolateral rotatory instability of the knee. J Bone Joint Surg Am 1985;67(3):3519. Crossref

4. Noyes FR and Barber-Westin SD. High tibial osteotmy in knees with associated chronic ligament deficiencies. In: Jackson DW, editor. Master Techniques in Orthopaedic Surgery. Reconstructive Knee Surgery, 3rd ed. Philadelphia: Lippincott Williams \& Wilkins, Wolters Kluwer; 2008. pp.315-59.

5. Eckhoff DG, Bach JM, Spitzer VM, Reinig KD, Bagur MM, Baldini TH, Flannery NMP. Three dimensional mechanics, kinematics and morphology of the knee viewed in virtual reality. J Bone Joint Surg Am 2005;87(Suppl 2):71-80. Crossref

6. Noyes FR, Schipplein OD, Andriacchi TP, Saddemi SR, Weise $M$. The anterior cruciate ligament deficient knee with varus alignment. An analysis of gait adaptations and dynamic joint loadings. Am J Sports Med 1992;20(6):707-16. Crossref 
7. Bombaci H, Canbora K, Onur G, Görgeç M. The effect of open wedge osteotomy on the posterior tibial slope. Acta Orthop Traumatol Turc 2005;39(5):404-10. http://www. aott.org.tr/en/the-effect-of-open-wedge-osteotomy-on-theposterior-tibial-slope- 164788

8. Shelburne KB, Kim HJ, Sterett WI, Pandy MG. Effect of posterior tibial slope on knee biomechanics during functional activity. J Orthop Res 2011;29(2):223-31. Crossref

9. Bernhardson AS, Aman ZS, Dornan GJ, Kemler BR, Storaci HW, Brady AW, Nakama GY, LaPrade RF. Tibial slope and its effect on force in anterior cruciate ligament grafts. Am J Sports Med 2019;47(2):296-302. Crossref

10. Kim GB, Kim K-I, Song SJ, Lee SH. Increased posterior tibial slope after medial open-wedge high tibial osteotomy may result in degenerative changes in anterior cruciate ligament. J Arthroplasty 2019;34(9):1922-8. Crossref

11. Marouane H, Shirazi-Adl A, Adopuni M, Hashemi J. Steeper posterior tibial slope markedly increases $A C L$ force in both active gait and passive knee joint under compression. J Biomech 2014;47(6):1353-9. Crossref

12. Giffin JR, Stabile KJ, Zantop T, Vogrin TM, Woo SL, Harner CD. Importance of tibial slope for stability of the posterior cruciate ligament deficient knee. Am J Sports Med 2007;35(9):1443-9. Crossref

13. Agneskirchner JD, Hurscheler C, Stukenborg-Colsman C, Imhoff AB, Lobenhoffer P. Effect of high tibial flexion osteotomy on cartilage pressure and joint kinematics: a biomechanical study in human cadaveric knees. Arch Orthop Trauma Surg 2004;124(9):575-84. Crossref

14. Brandon ML, Haynes PT, Bonamo JR, Flynn MI, Barrett GR, Sherman MF. The association between posterior-inferior tibial slope and anterior cruciate ligament insufficiency. Arthroscopy 2006;22(8):894-9. Crossref

15. Watanabe $\mathrm{Y}$, Takenada $\mathrm{N}$, Kinusaga $\mathrm{K}$, Matsushita $\mathrm{T}$, Teramoto T. Intra- and extra- articular deformity of lower limb: Tibial condylar valgus osteotomy (TCVO) and distal tibial oblique osteotomy (DTOO) for reconstruction of joint congruency. Adv Orthop 2019;2019:8605674. Crossref

16. Archbold P, Paillo JL. Surgical indications in the treatment of osteoarthritis. In: Neyret P, Demey G, editors. Surgery of the Knee. London: Springer; 2014. pp.131-8.

17. Liska F, von Deimling C, Otto A, Willinger L, Kellner R, Imhoff $A B$, Burgkart R, Voss A. Distal femoral torsional osteotomy increases the contact pressure of the medial patellafemoral joint in biomechanical analysis. Knee Surg Sports Traumatol Arthrosc 2019;27(7):2328-33. Crossref

18. ImhoffFB, Scheiderer B, Zakko P, Obopilwe E, Liska F, Imhoff $A B$, Mazzocca AD, Arciero RA, Beitzel K. How to avoid unintended valgus alignment in distal femoral derotational osteotomy for treatment of femoral torsional malalignment a concept study. BMC Musculoskelet Disord 2017;18(1):553. Crossref
19. Esenkaya I, Unay K. Proximal medial tibial biplanar retrotubercule open wedge osteotomy in medial knee arthrosis. Knee 2012;19(4):416-21. Crossref

20. Kloos F, Becher C, Fleischer B, Feucht MJ, Hohloch L, Südkamp, Niemeyer P, Bode G. High tibial osteotomy increases patellafemoral pressure if adverted proximal, while open-wedge HTO with distal biplanar osteotomy discharges the patellofemoral joint: different open-wedge high tibial osteotomies compared to an extra-articular unloading device. Knee Surg Sports Traumatol Arthrosc 2019;27(7):2334-44. Crossref

21. Yamaguchi KT, Cheung EC, Markolf KL, Boguszewski DV, Mathew J, Lama CJ, McAllister DR, Petrigliano FA. Effects of anterior closing wedge tibial osteotomy on anterior cruciate ligament force and knee kinematics. Am J Sports Med 2018;46(2):370-7. Crossref

22. Güneş T, Şen C, Bostan B, Erdem M, Kalaycıoğlu A. Proksimal tibiya açık fokal kubbe osteotomisinin diz eklemi mediyal laksitesi üzerine etkinliği. Joint Dis Rel Surg 2008;19(2):72-7. http://www.tevak.org/pdf/dergi/2008/pdfsno2/19_2_05.pdf

23. Brinkman J-M, Freiling $D$, Lobenhoffer $P$, Staubli $A E$, van Heerwaarden RJ. Supracondylar femur osteotomies around knee. Orthopade 2014;43(11):988-99. Crossref

24. Pietsch $M$, Hochegger $M$, Winkler $M$, Sandriesser $S$, Freude $\mathrm{T}$, Augat P. Opening-wedge osteotomies of the distal femur: minor advantages for a biplanar compared to a uniplanar technique. Knee Surg Sports Traumatol Arthrosc 2019;27(7):2375-84. Crossref

25. Rosso F, Margheritini F. Distal femoral osteotomy. Curr Rev Musculoskelet Med 2014;7(4):302-11. Crossref

26. van de Woude JAD, Spruijt S, van Ginneken BTJ, van Heerwaarden RJ. Distal femoral valgus osteotomy: bone healing time in single plane and biplanar technique. Strat Traum Limb Recon 2016;11(3):177-86. Crossref

27. Wylie JD, Jones DL, Hartley MK, Kapron AL, Krych AJ, Aoki SK, Maak TG. Distal femoral osteotomy for the valgus knee: medial closing wedge versus lateral opening wedge: A systemic review. Arthroscopy 2016;32(10):2141-7. Crossref

28. Kim YC, Yang J-H, Kim HJ, Tawonsawatruk T, Chang YS, Lee JS, Bhandare NN, Kim KS, Delgado GDG, Nha KW. Distal femoral varus osteotomy for valgus arthritis of the knees: systematic review of open versus closed wedge osteotomy. Knee Surg Relat Res 2018;30(1):3-16. Crossref

29. Quirno M, Campbell KA, Singh B, Hasan S, Jazrawi L, Kummer F, Strauss EJ. Distal femoral varus osteotomy for unloading valgus knee malalignment: a biomechanical analysis. Knee Surg Sports Traumatol Arthrosc 2017;25(3):863-8. Crossref

30. Lenhart RL, Smith CR, Schwartz MH, Novacheck TF, Thelen DG. The effect of distal femoral extension osteotomy on muscle lengths after surgery. J Child Orthop 2017;11(6):4728. Crossref 